\title{
Melatonin Induces Neuroprotection via System Xc Regulation in Neural Stem Cells
}

\author{
Melinda Clarke ${ }^{1}$, Stephanie Crockett $^{1}$ and Brian Sims ${ }^{1,2,3 *}$ \\ ${ }^{1}$ Departments of Pediatrics, Division of Neonatology, UAB, 619 20th Street South, 525 New Hillman Building, Birmingham, Alabama 35294, USA \\ ${ }^{2}$ Cell Biology, UAB, 619 20th Street South, 525 New Hillman Building, Birmingham, Alabama 35294, USA \\ ${ }^{3}$ Center for Glial Biology in Medicine, UAB, 619 20th Street South, 525 New Hillman Building, Birmingham, Alabama 35294, USA
}

\begin{abstract}
Hypoxic-brain injury is a major cause of neonatal morbidity and mortality. However, melatonin ( $\mathrm{N}$-acetyl-5methoxytryptamine) has been identified as an indirect anti-oxidant and direct free radical scavenger that could possibly reduce the injurious effects of hypoxic-ischemic brain injury in neonatal infants. Hypoxia-ischemia leads to multiple consequences such as an increase in extracellular glutamate. Yet the many mechanisms involved in melatonin-induced neuroprotection are still under investigation. We have hypothesized that melatonin could induce neuroprotection by increasing levels of cystine glutamate exchanger (xCT), an amino acid transporter as shown in previous work in our laboratory. Mouse neural stem cells were used for all in vitro studies for western blot analysis. In dose-response studies, melatonin increases xCT expression by $2.43 \pm 0.81,3.58 \pm 0.6,3.21 \pm 1.13,3.30 \pm 0.96$ and $3.48 \pm 0.30(p<0.01)$ folds at $1 \mathrm{nM}, 10 \mathrm{nM}, 100 \mathrm{nM}, 1 \mu \mathrm{M}$ and $10 \mu \mathrm{M}$ concentrations respectively in neural stem cells. In time-course studies, melatonin increases xCT by $2.60 \pm 0.97,2.65 \pm 0.27,3.29 \pm 0.40$, and $3.57 \pm 0.60$ fold at 4 hours, 8 hours, 12 hours, and 24 hours. Melatonin increases cystine uptake. System Xc inhibition decreased cell viability. These results suggest that melatonin may induce neuroprotection by increasing xCT expression and activity.
\end{abstract}

Keywords: Melatonin; Cystine Glutamate Exchanger; xCT; Neuroprotection

\section{Introduction}

Melatonin is a hormone secreted by the pineal gland and other organs and is well known for it's role in circadian rhythm [1]. Melatonin is an endogenous indoleamine that has strong antioxidant capabilities. Extrapineal melatonin secreted can cross the blood brain barrier to have a CNS effect due to the amphilicity of melatonin. This feature makes melatonin an attractive agent for neuroprotection.

Melatonin has many cellular functions that may lead to neuroprotection in the brain. For instance, regulating both neuronal and inducible nitric oxide synthase $[2,3]$. Other proteins are also regulated by melatonin including heme oxygenase-1 which in the presence of reservetrol causes neuroprotection [4]. BDNF alone has neurotrophic effects and melatonin was shown to increase these levels in mouse cerebellar neurons [5]. Cellular regulation of the melatonin receptors by valproic acid has been shown to be neuroprotective [6]. Antagonist of GABA (A) like receptors blocks melatonin induced neuroprotection [7]. Intracellular signaling through phosphatidyl inositol-3 kinase/ Akt signaling is involved in acute melatonin treatment and chronic treatment seems to be linked to ERK $1 / 2$ and JNK-1 and -2 [8].

Melatonin's use has been studied in various disease models. In $\beta$-amyloid toxicity melatonin regulates protein kinases [9]. In an experimental rodent model of Parkinson melatonin causes a decrease in 6-hydroxydopamine and a subsequent decrease in pathology [10]. Astrocytoma cell death is inhibited by melatonin and is dependent on phospholipase C signaling [11]. Melatonin increased the levels of antioxidants including glutathione (GSH) in ischemic brain injury in ovariectomized rats [12]. In the same study, HSP70 expression was also noted to be increased [12]. GDNF mRNA is increased by melatonin administration in glioma cells leading to cellular protection. Adenylate cyclase inhibition blocks the neuroprotective effects of melatonin in periventricular white matter [13].
One thought is that melatonin has a direct effect on glutathione biosynthesis. In an experimental model of subarachnoid hemorrhage, melatonin caused an increase in glutathione levels [14]. Glutamate induced cell injury is inhibited by melatonin which may involve the glutathione pathway in HT22 hippocampal cells. Melatonin did not increase GSH in astrocytes but the nanomolar concentration of melatonin required the presence of glutathione to have effective neuroprotection [15]. Rats exposed to hypoxia had increased glutathione after melatonin administration [16]. In brains exposed to irradiation cortical glutathione was increased during oxidative injury [17]. In a rat model of hydrocephalus melatonin treated brains had increased GSH levels [18]. Glutathione peroxidase is increased after melatonin treatment in rats $[19,20]$. Oxidative stress is relieved by an increase in glutathione peroxidase by melatonin in hyperhomocystenemic rats [21]. Fetal rat brain showed an increase in glutathione peroxidase after melatonin treatment [22-24].

To investigate the role of melatonin on glutathione biosynthesis, the rate limiting step needs to be examined. Glutathione biosynthesis, has a rate limiting step which is the importation of cystine. This is accomplished through the cystine glutamate antiporter (System $\mathrm{Xc}$ ). System Xc- is a pivotal transmembrane protein involved in the equimolar import of cystine and the external transport of glutamate. There are 2 subunits which comprise System Xc-, the regulatory subunit

*Corresponding author: Brian Sims MD, PhD, Departments of Pediatrics, Division of Neonatology, UAB, 619 20th Street South, 525 New Hillman Building, Birmingham Alabama 35294, USA, Tel: 205-975-5023; Fax: 205-934-3100; E-Mail: bsims@peds. uab.edu

Received April 04, 2012; Accepted May 02, 2012; Published May 04, 2012

Citation: Clarke M, Crockett S, Sims B (2012) Melatonin Induces Neuroprotection via System Xc Regulation in Neural Stem Cells. J Stem Cell Res Ther 2:120 doi:10.4172/2157-7633.1000120

Copyright: () 2012 Clarke M, et al. This is an open-access article distributed unde the terms of the Creative Commons Attribution License, which permits unrestricted use, distribution, and reproduction in any medium, provided the original author and source are credited. 
(4F2hc-CD98) and the catalytic subunit (xCT). CD98 is a regulatory subunit for multiple transporters. xCT consists of 12 transmembrane regions and is considered the functional unit of the protein. Thus, $\mathrm{xCT}$ and System Xc- are used interchangeably.

Recent studies have shown that $\mathrm{xCT}$ increases glutathione. $\mathrm{xCT}$ has been proposed as a potential critical regulator in cellular protection in retinal ganglion cells [25]. Recently, multiple agents have been identified as regulators of xCT activity including erythropoietin [26] and all trans retinoic acid [27] through an increase in glutathione. System Xc regulation leads to neuroprotection in neural stem cells $[26,27]$. Hypoxic preconditioning is a method of neuroprotection and system Xc- inhibition leads to a decrease in cell viability (Sims 2011-Accepted). Insight into system Xc- regulation could potentially lead to neuroprotective strategies. Since melatonin's neuroprotective mechanism is still unclear it is plausible that it may involve system Xc-.

\section{Materials and Methods}

All equipment and chemical used were from BioRad and Sigma Chemical Company (St. Louis, MO) respectively unless otherwise stated.

\section{Cell culture}

Neural stem cells (Catalog Number SCR029) were obtained from Chemicon as Cryopreserved Mouse Cortical Neural Stem Cells. Polyornithine $(10 \mathrm{mg} / \mathrm{ml})$ - Laminin $(5 \mu \mathrm{g} / \mathrm{ml})$ overnight coated plates were washed and used to seed cells or stored at $-80^{\circ} \mathrm{C}$ until time of experiment. Neural stem cells were cultured and passaged according to the manufacture's protocol. In brief, cells were grown in Neural Stem Cell Expansion Medium and supplemented with Fibroblast Growth Factor 2 (FGF-2) $20 \mathrm{ng} / \mathrm{ml}$, Epidermal Growth Factor (EGF) $20 \mathrm{ng} /$ $\mathrm{ml}$, and heparin $2 \mathrm{~g} / \mathrm{ml}$ ). Cells were passaged every 3-5 days or at $80 \%$ confluence in to T25 cm flasks at a 1:3 ratio. Differentiation, done after the passage 3 , was induced by media without supplemental growth factors.

\section{Cell death/viability assay}

Cells were treated with $3 \mathrm{mM}$ of glutamate to induce cell death by glutamate toxicity. This dose point was previously established in Sims et al. [26]. Total cell count was determined using a standard hemocytometer and Trypan Blue in all experiments.

\section{Protein concentration}

To determine protein sample concentrations, the Bio-Rad $D_{C}$ Protein Assay was used, and the absorbencies read out at $750 \mathrm{~nm}$ on a SmartSpec ${ }^{\mathrm{TM}}$ Plus spectrophotometer.

\section{Western blot}

Cells were collected at the endpoint and lysed with RIPA buffer. $50 \mu \mathrm{g}$ of protein was collected and ran on a Bio-Rad Ready Gel Tris $10 \%$ HCL. Samples were ran at $120 \mathrm{~V}$ for 60 minutes on ice. Gel was transferred to nitrocellulose using the Trans Blot Semi-Dry apparatus for 15 minutes at $15 \mathrm{~V}$. Blots were washed three times with TBS- $0.1 \%$ Tween (TBST). Membranes were blocked in a $0.1 \%$ milk solution. Primary antibodies were used at 1:1000 dilutions in $0.1 \%$ milk. Primary antibodies used were Actin (MAB1501-Chemicon) and System Xc (Novus Biological). Secondary antibody was used at a 1:1000 dilution. After washing, blots were developed using the Pierce Super Signal detection kit and developed on film with the Kodak developer.

\section{Cystine uptake assay and detection}

The standard cystine uptake protocol, described in Sims et al. [26], was followed with the following modification described in Nakagawa et al. [28]. Cells were grown to $80 \%$ confluence in 6 wells plates and then treated overnight with melatonin. The cells were washed three times with phosphate buffered saline then cystine uptake buffer (122 $\mathrm{mM}$ choline-chloride, $1.8 \mathrm{mM} \mathrm{KCl}, 1.3 \mathrm{mM} \mathrm{CaCl}, 1.2 \mathrm{mM}$ potassium phosphate, $25 \mathrm{mM}$ Triethylammonium bicarbonate, $10 \mathrm{mM}$ glucose, $0.4 \mathrm{mM}$ magnesium sulfate and adjusted to $\mathrm{pH} 7.4$ ) added with $1 \mu \mathrm{M}$ cystine for 1 hour. After an hour $400 \mu \mathrm{l}$ of supernatant was placed in a cuvette. $100 \mu \mathrm{l}$ of ddH 0 and $1.0 \mathrm{ml} 150 \mathrm{mM}$ choline chloride added in the presence of $300 \mu \mathrm{l}$ of $10 \%$ sodium cyanide for 20 minutes at room temperature. $100 \mu \mathrm{l}$ of $20 \%$ sodium nitroprusside added to solution and assayed within a minute at $521 \mathrm{~nm}$ on the BIO-RAD SmartSpec Plus spectrophotometer. A cystine standard curve needs to be made using cold cystine to quantify cystine uptake.

\section{Statistical analysis}

Statistical analysis was performed using the Student t-test comparing all samples to control. Data are presented as mean \pm standard deviation with each experiment being done in triplicate. Statistical significance was set at $\mathrm{p} \leq 0.05$.

\section{Results}

Melatonin has been shown to affect several proteins and pathways including those that affect glutathione biosynthesis. In an effort to demonstrate melatonin's role in glutathione biosynthesis we used in vitro experiments to demonstrate that melatonin affects a critical protein involved in glutathione biosynthesis, System Xc. Figure 1A demonstrates that increasing concentrations of melatonin also regulate $\mathrm{xCT}$ protein levels and Figure $1 \mathrm{~B}$ shows graph of densitometric analysis of $\mathrm{xCT}$ normalized to actin. In Figure 2A, we show that a concentration of $10 \mathrm{nM}$ melatonin increases XCT protein in a time dependent fashion as shown at $4,8,12$ and 24 hours, $\mathrm{p} \leq 0.05$. The $\mathrm{xCT} /$ actin ratio of this effect is demonstrated in Figure 2B.

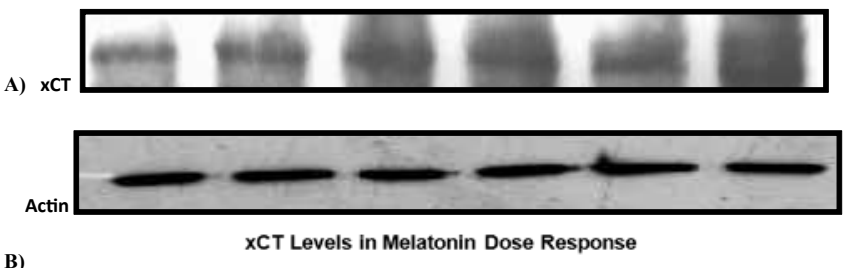

B)

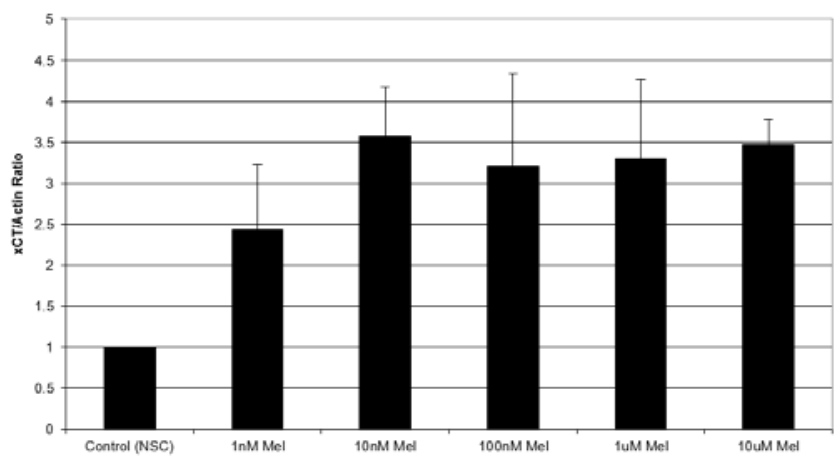

Figure 1: Melatonin time-dependent effect on System $X_{c}$ in neural stem cells All experiments were $n=3$. A.) Western Blot probed for $x C T$ and actin. B.) Graphical representation of densitometric analysis of XCT and actin ratio. 
Melatonin's role in glutathione production has been reported [17,18,29-34]. However, there is no direct evidence that melatonin regulates cystine uptake, the critical step in glutathione biosynthesis. In Figure 3 we show that cystine uptake is directly affected by melatonin. The effect exhibits a statistical increase in cystine uptake.

Melatonin's neuroprotective role has been demonstrated in several experiments synthase $[2,3]$. We performed an experiment in neural stem cells where we induced cell death by using high concentrations of glutamate. In this study, cells were also exposed to 3 different concentrations of melatonin with and without S4-CPG (Figure 4). 3 $\mathrm{mM}$ glutamate caused a significant decrease in cell viability and this decrease is blocked by melatonin supplementation. In the presence of the inhibitor S4-CPG, there is increased cell death.

A)
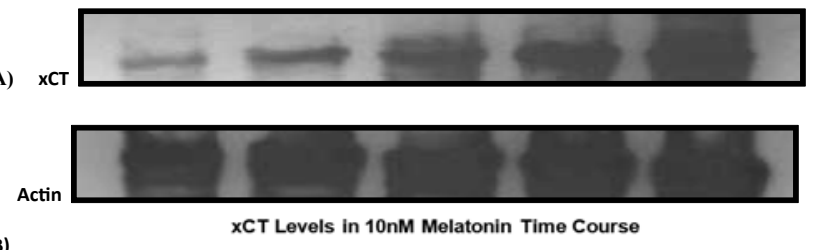

B)

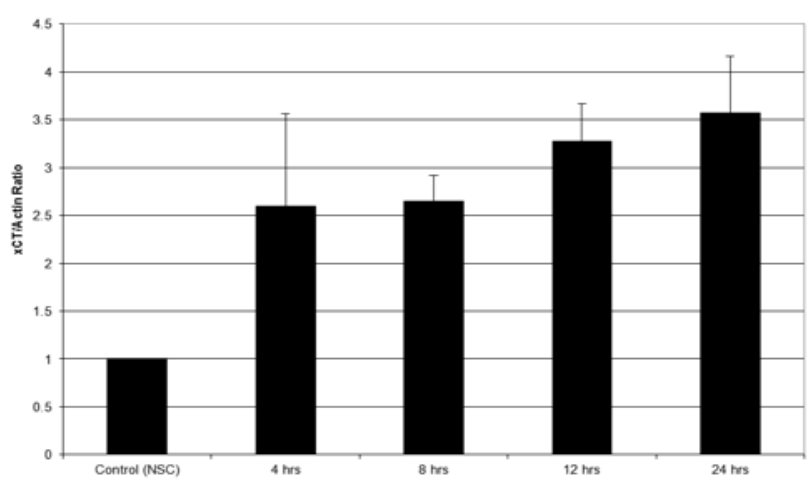

Figure 2: Melatonin dose effect on System $X_{c}$ in neural stem cells. All experiments were $n=3$. A.) Western Blot probed for $x C T$ and actin. B.) Graphical representation of densitometric analysis of $\mathrm{XCT}$ and actin ratio.

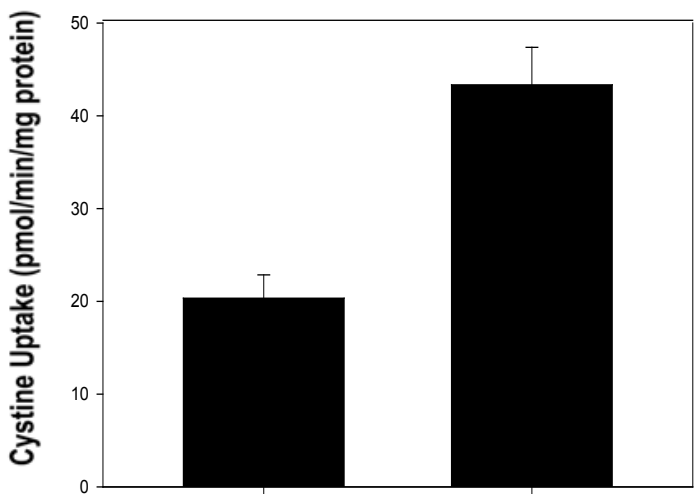

Control

10nM Melatonin

Figure 3: Melatonin effect on cystine uptake. NSC cells were treated with $10 \mathrm{nM}$ Melatonin overnight. Cystine uptake was detected using a cyanide nitroprusside system and read at $521 \mathrm{~nm}$. Cystine uptake is expressed as pmols $/ \mathrm{min} / \mathrm{mg}$ protein. ${ }^{*} \mathrm{p} \leq 0.05$ using the paired student t-test. All experiments were $n=3$.

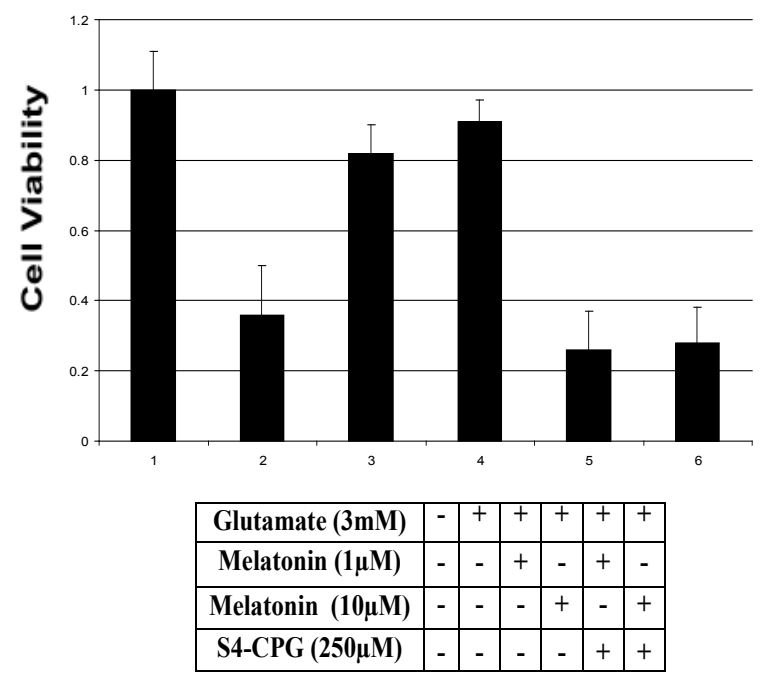

Figure 4: Melatonin-induced neuroprotection is attenuated by System $\mathrm{Xc}_{\mathrm{c}}$ inhibition with S4- carboxyphenylglycine. Glutamate at $3 \mathrm{mM}$ was used to induce apoptosis in all experimental conditions. ${ }^{*} p \leq 0.05$ using the paired student $\mathrm{t}$-test. All experiments were $\mathrm{n}=3$.

\section{Discussion}

Melatonin levels interestingly have been measured in injured brains is increased/decreased and may represent a mechanism that is worthy of intense investigation. Neonatal brains are very vulnerable and have lower levels of melatonin compared to the fetus [35] and may benefit from melatonin supplementation. Over the years the body makes less melatonin predisposing the aging brain to less endogenous neuroprotection [36]. The mechanisms to date have been unclear. Here we demonstrate that melatonin has an important role in regulating System Xc.

The time and dose dependent regulation of System Xc makes this regulation physiologically relevant due to the rapid increase in protein. Therefore, if the brain is injured melatonin has the potential of inducing neuroprotection within a 4 hour window. This window may prove to be beneficial in the clinical setting allowing for an increase in cellular protection in a timely fashion. In other studies, erythropoietin [26] and retinoic acid [27] have a similar profile when it comes to System Xc regulation.

There are several models of cellular stress but here we show that glutamate-induced cell death can be decreased by melatonin supplemetation. Increased extracellular glutamate is a finding seen in hypoxia ischemia and is a very relevant physiological consideration. Melatonin can be produced in other regions of the body and be detectable in the CNS so melatonin distribution is achieved. Supplementation remains a practical approach to attenuation of brain injury.

System Xc regulation continues to be a potent regulator of neuroprotection. Melatonin now is linked to regulating this important protein. Melatonin may regulate this protein through various pathways. There may be a direct or an indirect effect on System Xc via melatonin. Understanding how this protein interacts with melatonin is currently under investigation in out laboratory. As we learn more about this protein it may be crucial in developing a neuroprotective pathway that can be used for multiple neurological conditions. 
Citation: Clarke M, Crockett S, Sims B (2012) Melatonin Induces Neuroprotection via System Xc Regulation in Neural Stem Cells. J Stem Cell Res Ther 2:120. doi:10.4172/2157-7633.1000120

\section{Acknowledgement}

Funding for this project was provided by the Robert Wood Johnson Harold Amos Medical Faculty Development Award and the CHRC K12 NICHD Training Grant.

\section{References}

1. Hardeland R (2010) Melatonin metabolism in the central nervous system. Curr Neuropharmacol 8: 168-181.

2. Dong WG, Mei Q, Yu JP, Xu JM, Xiang L, et al. (2003) Effects of melatonin on the expression of iNOS and COX-2 in rat models of colitis. World $J$ Gastroenterol 9: 1307-1311.

3. Koh PO (2008) Melatonin regulates nitric oxide synthase expression in ischemic brain injury. J Vet Med Sci 70: 747-750.

4. Kwon KJ, Kim JN, Kim MK, Lee J, Ignarro LJ, et al. (2011) Melatonin synergistically increases resveratrol-induced heme oxygenase-1 expression through the inhibition of ubiquitin-dependent proteasome pathway: a possible role in neuroprotection. J Pineal Res 50: 110-123.

5. Imbesi M, Uz T, Manev H (2008) Role of melatonin receptors in the effects of melatonin on BDNF and neuroprotection in mouse cerebellar neurons. J Neural Transm 115: 1495-1499.

6. Castro LM, Gallant M, Niles LP (2005) Novel targets for valproic acid: upregulation of melatonin receptors and neurotrophic factors in $\mathrm{C} 6$ glioma cells. J Neurochem 95: 1227-1236.

7. Paula-Lima AC, Louzada PR, De Mello FG, Ferreira ST (2003) Neuroprotection against Abeta and glutamate toxicity by melatonin: are GABA receptors involved? Neurotox Res 5: 323-327.

8. Kilic U, Kilic E, Reiter RJ, Bassetti CL, Hermann DM (2005) Signal transduction pathways involved in melatonin-induced neuroprotection after focal cerebra ischemia in mice. J Pineal Res 38: 67-71.

9. Kwon KJ, Kim HJ, Shin CY, Han SH (2010) Melatonin Potentiates the Neuroprotective Properties of Resveratrol Against Beta-Amyloid-Induced Neurodegeneration by Modulating AMP-Activated Protein Kinase Pathways. J Clin Neurol 6: 127-137.

10. Borah A, Mohanakumar KP (2009) Melatonin inhibits 6-hydroxydopamine production in the brain to protect against experimental parkinsonism in rodents. J Pineal Res 47: 293-300.

11. [Radogna F, Nuccitelli S, Mengoni F, Ghibelli L (2009) Neuroprotection by melatonin on astrocytoma cell death. Ann N Y Acad Sci 1171: 509-513.

12. Ozacmak VH, Barut F, Ozacmak HS (2009) Melatonin provides neuroprotection by reducing oxidative stress and HSP70 expression during chronic cerebra hypoperfusion in ovariectomized rats. J Pineal Res 47: 156-163.

13. Husson I, Mesples B, Bac P, Vamecq J, Evrard P, et al. (2002) Melatoninergic neuroprotection of the murine periventricular white matter against neonatal excitotoxic challenge. Ann Neurol 51: 82-92.

14. Ersahin M, Toklu HZ, Cetinel S, Yuksel M, Yegen BC, et al. (2009) Melatonin reduces experimental subarachnoid hemorrhage-induced oxidative brain damage and neurological symptoms. J Pineal Res 46: 324-332.

15. Martin V, Sainz RM, Antolin I, Mayo JC, Herrera F, et al. (2002) Severa antioxidant pathways are involved in astrocyte protection by melatonin. J Pineal Res 33: 204-212.

16. Kaur C, Sivakumar V, Ling EA (2010) Melatonin protects periventricular white matter from damage due to hypoxia. J Pineal Res 48: 185-193.

17. Yildirim O, Comoglu S, Yardimci S, Akmansu M, Bozkurt G, et al. (2008) Preserving effects of melatonin on the levels of glutathione and malondialdehyde in rats exposed to irradiation. Gen Physiol Biophys 27: 32-37.

18. Turgut M, Erdogan S, Ergin K, Serter M (2007) Melatonin ameliorates bloodbrain barrier permeability, glutathione, and nitric oxide levels in the choroid plexus of the infantile rats with kaolin-induced hydrocephalus. Brain Res 1175 $117-125$

19. Subramanian P, Mirunalini S, Pandi-Perumal SR, Trakht I, Cardinali DP (2007) Melatonin treatment improves the antioxidant status and decreases lipid content in brain and liver of rats. Eur J Pharmacol 571: 116-119.

20. Cruz A, Tunez I, Martinez R, Munoz-Castaneda JR, Ramirez LM, et al. (2007) Melatonin prevents brain oxidative stress induced by obstructive jaundice in rats. J Neurosci Res 85: 3652-3656.
21. Baydas G, Ozer M, Yasar A, Koz ST, Tuzcu M (2006) Melatonin prevents oxidative stress and inhibits reactive gliosis induced by hyperhomocysteinemia in rats. Biochemistry 71: S91-S95.

22. Wakatsuki A, Okatani Y, Shinohara K, Ikenoue N, Kaneda C, et al. (2001) Melatonin protects fetal rat brain against oxidative mitochondrial damage. $J$ Pineal Res 30: 22-28.

23. Okatani Y, Wakatsuki A, Kaneda C (2000) Melatonin increases activities of glutathione peroxidase and superoxide dismutase in fetal rat brain. J Pinea Res 28: 89-96.

24. Kotler M, Rodriguez C, Sainz RM, Antolin I, Menendez-Pelaez A (1998) Melatonin increases gene expression for antioxidant enzymes in rat brain cortex. J Pineal Res 24: 83-89.

25. Dun Y, Mysona B, Van Ells T, Amarnath L, Ola MS, et al. (2006) Expression of the cystine-glutamate exchanger (xc-) in retinal ganglion cells and regulation by nitric oxide and oxidative stress. Cell Tissue Res 324: 189-202.

26. Sims B, Clarke M, Njah W, Hopkins ES, Sontheimer H (2010) Erythropoietininduced neuroprotection requires cystine glutamate exchanger activity. Brain Res 1321: 88-95.

27. Crockett S, Clarke M, Reeves S, Sims B (2011) Cystine glutamate exchange upregulation by retinoic acid induces neuroprotection in neural stem cells Neuroreport 22: 598-602.

28. Nakagawa Y, Coe FL (1999) A modified cyanide-nitroprusside method for quantifying urinary cystine concentration that corrects for creatinine interference. Clin Chim Acta 289: 57-68.

29. Floreani M, Skaper SD, Facci L, Lipartiti M, Giusti P (1997) Melatonin maintains glutathione homeostasis in kainic acid-exposed rat brain tissues. Faseb $\mathrm{J} 11$ : 1309-1315.

30. Gonca Akbulut K, Gonu I B, Akbulut H (1999) Differential effects of pharmacological doses of melatonin on malondialdehyde and glutathione levels in young and old rats. Gerontology 45: 67-71.

31. Gupta YK, Gupta M, Kohli K (2003) Neuroprotective role of melatonin in oxidative stress vulnerable brain. Indian J Physiol Pharmacol 47: 373-386.

32. Mollaoglu H, Topal T, Ozler M, Uysal B, Reiter RJ, et al. (2007) Antioxidant effects of melatonin in rats during chronic exposure to hyperbaric oxygen. $J$ Pineal Res 42: 50-54.

33. Pablos MI, Agapito MT, Gutierrez R, Recio JM, Reiter RJ, et al. (1995) Melatonin stimulates the activity of the detoxifying enzyme glutathione peroxidase in several tissues of chicks. J Pineal Res 19: 111-115.

34. Szaroma W, Dziubek K (2011) Changes in the amount of reduced glutathione and activity of antioxidant enzymes in chosen mouse organs influenced by zymosan and melatonin administration. Acta Biol Hung 62: 133-141.

35. Ogasawara T, Adachi N, Nishijima M (1991) Melatonin levels in maternal plasma before and during delivery, and in fetal and neonatal plasma. Nihon Sanka Fujinka Gakkai zasshi 43: 335-341.

36. Liu RY, Zhou JN, van Heerikhuize J, Hofman MA, Swaab DF (1999) Decreased melatonin levels in postmortem cerebrospinal fluid in relation to aging, Alzheimer's disease, and apolipoprotein E-epsilon4/4 genotype. J Clin Endocrinol Metab 84: 323-327. 